\title{
On the stability of equilibrium for a reformulated foreign trade model of three countries
}

\author{
Ioannis K. Dassios • Grigoris Kalogeropoulos
}

Received: 11 February 2014/ Accepted: 7 June 2014/Published online: 27 June 2014

(C) The Author(s) 2014. This article is published with open access at Springerlink.com

\begin{abstract}
In this paper, we study the stability of equilibrium for a foreign trade model consisting of three countries. As the gravity equation has been proven an excellent tool of analysis and adequately stable over time and space all over the world, we further enhance the problem to three masses. We use the basic Structure of Heckscher-Ohlin-Samuelson model. The national income equals consumption outlays plus investment plus exports minus imports. The proposed reformulation of the problem focus on two basic concepts: (1) the delay inherited in our economic variables and (2) the interaction effect along the three economies involved. Stability and stabilizability conditions are investigated while numerical examples provide further insight and better understanding. Finally, a generalization of the gravity equation is somehow obtained for the model.
\end{abstract}

Keywords Mathematical modelling - Foreign trade model $\cdot$ Difference equations $\cdot$ Jury criterion

\section{Introduction}

Keynesian macroeconomics inspired the seminal work of Samuelson, see Samuelson (1939), who actually introduced the business cycle theory. In the past decades, many more sophisticated models for the national income of a country

I. K. Dassios ( $\square)$

School of Mathematics and Maxwell Institute, The University of Edinburgh, Mayfield Road, Edinburgh EH9 3JZ, UK

e-mail: jdasios@math.uoa.gr

G. Kalogeropoulos

Department of Mathematics, University of Athens, Athens, Greece have been proposed by other researchers (Anderson 1979; Anderson et al. 2003; Azzo and Houpis 1995; Chari 1994; Chow 1985; Dassios et al. 2012; Day 1999; Dorf 1983; Kuo 1996; Ogata 1987; Puu et al. 2004; Rosser 2000; Santos Silva and Silvana Tenreyro 2006; Westerhoff 2006; Wincoop 1996). All these models use superior and more delicate mechanisms involving monetary aspects, inventory issues, business expectation, borrowing constraints, welfare gains and multi-country consumption correlations. The basic shortcoming of most of these models is the incapability to produce a stable path for the national income when realistic values for the different parameters (multiplier and accelerator parameters) are entered into the system of equations. Of course, this statement contradicts with the empirical evidence which supports temporary or long-lasting business cycles.

The starting point of this paper is the reconsideration of the well-known gravity equation that appears in international trade modeling, see Anderson (1979), Anderson et al. (2003), Chaney (2008), Santos Silva and Silvana Tenreyro (2006). This reconstruction advances the whole analysis into the context of a system consisting of three countries. Actually, we design such a system and investigate the stability and stabilizability conditions. Keeping in mind that Newton's universal law of gravitation (describing the bilateral interaction of two masses) becomes quite complex when we consider the system of three masses, we may easily anticipate the complexity of our conditions for the system of three countries. Of course, apart the gravity equation, there are many other excellent approaches as regards the international trade and the respective modeling, see Alenikov et al. (1969), Brems (1956),Bond and Driskill (2009), Cabo et al. (2008, 2014), Chaney (2008, 2011), Dassios and Kontzalis (2012), Eaton et al. (0000), Gcke (2001), Hager and Garg (1972), Horiba and Moroney 
(1979), Huang et al. (2009), Jones (2012), Jones and Marjit (2009), Jones (1975), Kokot (2004), Korobko (2000), Koyck (1953), Krelle (1987), Krugman (1980), Luke and Breakwell (1978), Nagy and Stahl (1967), Mansur and Whalley (1982), Mikhalevich et al. (2001), Mycielski et al. (1963), Van der Laan (1990), Whalley and White (1985), Yano (1990), Yu et al. (2008), Zhu and Huang (2007). Although primitive and using only the demand point of view, the foreign trade model prospect still provides an excellent insight into the problem and justification of business cycles appearing in national economies.

In this article, we propose a new model incorporating delayed variables into the system of equations. The proposed modification succeeds to provide a more comprehensive explanation for the emergence of business cycles while also produce a stable trajectory for the expectation of the national income. Actually, it succeeds to model stable business cycles when realistic values of the multiplier and accelerator parameters are entered into the system of equations. So, we can safely deduce the fact that individuals and/or institutions base their decisions (for consumption or investment levels) upon the experience of the last 6 years.

The paper is organized as follows. In "Basic assumptions" we introduce the basic assumptions of the proposed model and in "The model" we show how it is constructed. In "Stability investigation" and "Controllability and state feedback", we study stability and stabilizability conditions respectively and in "Numerical example: system design andpractical implications" we provide numerical results.

\section{Basic assumptions}

Our foreign trade model for three countries is based on the following assumptions:

National income $T_{k}^{i}$ of the country $i$, for $i=1,2,3$ at time $k$, equals consumption outlays $C_{k}^{i}$ plus investment $I_{k}^{i}$ plus exports $X_{k}^{i}$ minus imports $M_{k}^{i}$.

$T_{k}^{1}=C_{k}^{1}+I_{k}^{1}+X_{k}^{1}-M_{k}^{1}$,

$T_{k}^{2}=C_{k}^{2}+I_{k}^{2}+X_{k}^{2}-M_{k}^{2}$,

$T_{k}^{3}=C_{k}^{3}+I_{k}^{3}+X_{k}^{3}-M_{k}^{3}$.

Assumption 2.1 Private investment of the country $i$, for $i=1,2,3$ at time $k, I_{k}^{i}$, depends on consumption changes and on the accelerator factor $b_{i}$, where $b_{i}>0$. Consequently, $I_{k}^{i}$ depends on consumption outlays changes,

$I_{k}^{1}=b_{1}\left(C_{k}^{1}-C_{k-1}^{1}\right)+G^{1}$,

$I_{k}^{2}=b_{2}\left(C_{k}^{2}-C_{k-1}^{2}\right)+G^{2}$,

$I_{k}^{3}=b_{3}\left(C_{k}^{3}-C_{k-1}^{3}\right)+G^{3}$. where $G^{1}, G^{2}$ and $G^{3}$ are fixed investment amounts. In Section 5 we consider $G^{1}, G^{2}$ and $G^{3}$ depending on $k$, denoting them as $G_{k}^{1}, G_{k}^{2}$ and $G_{k}^{3}$ and we investigate the corresponding control problem by considering as input vector $\bar{G}_{k}=\left[\begin{array}{lll}G_{k}^{1} & G_{k}^{2} & G_{k}^{3}\end{array}\right]$.

Assumption 2.2 Outlays for domestic consumption $D_{k}^{i}$ of country $i$, for $i=1,2,3$ at time $k$, equal total consumption $C_{k}$ of the country $i$ at time $k$ minus imports $M_{k}^{i}$.

$D_{k}^{1}=C_{k}^{1}-M_{k}^{1}$,

$D_{k}^{2}=C_{k}^{2}-M_{k}^{2}$,

$D_{k}^{3}=C_{k}^{3}-M_{k}^{3}$.

and by replacing (2) and (3) into (1)

$T_{k}^{1}=D_{k}^{1}+X_{k}^{1}+b_{1}\left(C_{k}^{1}-C_{k-1}^{1}\right)+G^{1}$,

$T_{k}^{2}=D_{k}^{2}+X_{k}^{2}+b_{2}\left(C_{k}^{2}-C_{k-1}^{2}\right)+G^{2}$,

$T_{k}^{3}=D_{k}^{3}+X_{k}^{3}+b_{3}\left(C_{k}^{3}-C_{k-1}^{3}\right)+G^{3}$.

Assumption 2.3 Outlays for domestic consumption $D_{k}^{i}$ of country $i$, for $i=1,2,3$ at time $k$, depend on past income (only on last year's value) and on marginal tendency to consume, modeled with $m_{i i}$, the multiplier parameter, where $0<m_{i i}<1$,

$D_{k}^{1}=m_{11} T_{k-1}^{1}$,

$D_{k}^{2}=m_{22} T_{k-1}^{2}$,

$D_{k}^{3}=m_{33} T_{k-1}^{3}$.

Assumption 2.4 Imports $M_{k}^{i}$ of country $i$, for $i=1,2,3$ at time $k$, depend on past income (only on last year's value) and on marginal tendency to consume, modeled with $m_{12}, m_{21}$ and $m_{13}$ the multiplier parameter, where $0<m_{12}, m_{21}, m_{13}<1$

$M_{k}^{1}=m_{12} T_{k-1}^{1}$,

$M_{k}^{2}=m_{21} T_{k-1}^{2}$,

$M_{k}^{3}=m_{13} T_{k-1}^{3}$.

Assumption 2.5 Since we consider three countries, the exports of one must be the linear sum of imports of the other two

$M_{k}^{1}=c_{1} X_{k}^{2}+c_{2} X_{k}^{3}$,
$M_{k}^{2}=d_{1} X_{k}^{1}+d_{2} X_{k}^{3}$,
$M_{k}^{3}=r_{1} X_{k}^{1}+r_{2} X_{k}^{2}$.

Note that

$c_{1}+r_{2}=1$,

$c_{2}+d_{2}=1$,

$r_{1}+d_{1}=1$.

where $c_{1}, c_{2}, d_{1}, d_{2}, r_{1}$ and $r_{2}$ constant and positive parameters. 


\section{The model}

In order to obtain our model, first we solve the linear system (7) and after we replace (8). Thus we obtain

$X_{k}^{1}=l_{1} M_{k}^{1}+l_{2} M_{k}^{2}+l_{3} M_{k}^{3}$,

$X_{k}^{2}=p_{1} M_{k}^{1}+p_{2} M_{k}^{2}+p_{3} M_{k}^{3}$,

$X_{k}^{3}=q_{1} M_{k}^{1}+q_{2 M_{k}^{2}}+q_{3} M_{k}^{3}$.

where

$$
\begin{aligned}
& \mu_{1}=p_{1} m_{12} \\
& \mu_{2}=m_{22}+b_{2}\left(m_{22}+m_{21}\right)+p_{2} m_{21}, \\
& \mu_{3}=p_{3} m_{13} \\
& \mu_{4}=-b_{2}\left(m_{22}+m_{21}\right) \\
& v_{1}=q_{1} m_{12} \\
& v_{2}=q_{2} m_{21} \\
& v_{3}=m_{33}+b_{3}\left(m_{33}+m_{13}\right)+q_{3} m_{13} \\
& v_{4}=-b_{3}\left(m_{33}+m_{13}\right)
\end{aligned}
$$

Furthermore by replacing (6) into (9) we get

$X_{k}^{1}=l_{1} m_{12} T_{k-1}^{1}+l_{2} m_{21} T_{k-1}^{2}+l_{3} m_{13} T_{k-1}^{3}$,

$X_{k}^{2}=p_{1} m_{12} T_{k-1}^{1}-p_{2} m_{21} T_{k-1}^{2}+p_{3} m_{13} T_{k-1}^{3}$,

$X_{k}^{3}=q_{1} m_{12} T_{k-1}^{1}+q_{2} m_{21} T_{k-1}^{2}+q_{3} m_{13} T_{k-1}^{3}$.

Finally by applying (11) and (5) into the system (4) we arrive at the following linear discrete time system

$T_{k+2}=M_{1} T_{k+1}+M_{0} T_{k}+G$.

where

$$
\begin{aligned}
& T_{k}=\left[\begin{array}{l}
T_{k}^{1} \\
T_{k}^{2} \\
T_{k}^{3}
\end{array}\right], G=\left[\begin{array}{l}
G^{1} \\
G^{2} \\
G^{3}
\end{array}\right], \\
& M_{1}=\left[\begin{array}{lll}
\lambda_{1} & \lambda_{2} & \lambda_{3} \\
\mu_{1} & \mu_{2} & \mu_{3} \\
v_{1} & v_{2} & v_{3}
\end{array}\right], \\
& M_{0}=\left[\begin{array}{ccc}
\lambda_{4} & 0 & 0 \\
0 & \mu_{4} & 0 \\
0 & 0 & v_{4}
\end{array}\right]
\end{aligned}
$$

and

$$
\begin{aligned}
& \lambda_{1}=m_{11}+b_{1}\left(m_{11}+m_{12}\right)+l_{1} m_{12}, \\
& \lambda_{2}=l_{2} m_{21}, \\
& \lambda_{3}=l_{3} m_{13}, \\
& \lambda_{4}=-b_{1}\left(m_{11}+m_{12}\right),
\end{aligned}
$$

Practical justification for the reformulated model

In this subsection, we provide some practical justification for the new assumptions of our reformulated model. Actually we may state the following arguments:

1. The delayed model (or memory model) is quite interesting from the mathematical point of view. The sixth order polynomials produce oscillatory trajectories for the solutions and consequently for the national income values.

2. The delay concept has been also suggested by previous papers. We refer to Chow (1985) who suggests the delayed information as a tool to explain and support the statistical data of chinese economy for the years 1932-1982.

3. The national accounts of main countries are closing with substantial time delay after the calendar year end. So, the information used in next year's accounts are estimations or closed values from past years.

4. Delayed information may be used in financial projections of national accounts.

5. Consumption may depend not only on current year's experience but also on previous years. Customers remember the level of their income not only of the current year but also from previous years. So, they adjust their behavior accordingly.

6. Private investment may also consider the level of national economy of previous years. An investor keeps in mind not only the current level of economy but the time sequence and the corresponding trajectory of national economy all the recent years. 
7. The multiplier and accelerator factors are not constant over time but may fluctuate and most probably behave as random variables.

\section{Stability investigation}

For $I_{3}-M_{1}-M_{0}$ non-singular let

$S_{e}=\left(I_{3}-M_{1}-M_{0}\right)^{-1} G$

be the equilibrium of the system (12). In this Section, we will study necessary and sufficient conditions for the national income matrix $T_{k}$ to approach a matrix of constant equilibrium values independently of the initial matrix $T_{0}$ so that

$\lim _{k \longrightarrow+\infty} T_{k}=\left(I_{3}-M_{1}-M_{0}\right)^{-1} G$.

To discover conditions under which we may be sure that (15) is satisfied, we must study the characteristic values (eigenvalues) of the matrix pencil $z^{2} I_{3}-M_{1} z-M_{0}$. Thus by investigating the stability of system (12) we arrive at the following Theorem.

Theorem 4.1 Consider the system (12) and let

$$
\begin{aligned}
a_{0}= & 1, \\
a_{1}= & -\lambda_{1}-\mu_{2}-v_{3}, \\
a_{2}= & -\lambda_{4}-\mu_{4}-v_{4}+\lambda_{1} \mu_{2}-\lambda_{2} \mu_{1}-\lambda_{3} v_{1}-\mu_{3} v_{2} \\
& +\lambda_{1} v_{3}+\mu_{2} v_{3}, \\
a_{3}= & \mu_{4} \lambda_{1}+v_{4} \lambda_{1}+\lambda_{4} \mu_{2}+v_{4} \mu_{2}+\lambda_{3} \mu_{2} v_{1}-\lambda_{2} \mu_{3} v_{1} \\
& -\lambda_{3} \mu_{1} v_{2}+\lambda_{1} \mu_{3} v_{2}+\lambda_{4} v_{3}+\mu_{4} v_{3}-\lambda_{1} \mu_{2} v_{3}+\lambda_{2} \mu_{1} v_{3}, \\
a_{4}= & \lambda_{4} \mu_{4}+\lambda_{4} v_{4}+\mu_{4} v_{4}-v_{4} \lambda_{1} \mu_{2}+v_{4} \lambda_{2} \mu_{1}+\mu_{4} \lambda_{3} v_{1} \\
& +\lambda_{4} \mu_{3} v_{2}-\mu_{4} \lambda_{1} v_{3}-\lambda_{4} \mu_{2} v_{3}, \\
a_{5}= & -\mu_{4} v_{4} \lambda_{1}-\lambda_{4} v_{4} \mu_{2}-\lambda_{4} \mu_{4} v_{3}, \\
a_{6}= & -\lambda_{4} \mu_{4} v_{4} .
\end{aligned}
$$

Then for $I_{3}-M_{1}-M_{0}$ non-singular, the unique equilibrium (14) is asymptotically stable if and only if

1.

$$
\left|\operatorname{det}\left(\begin{array}{cc}
0_{3,3} & I_{3} \\
M_{0} & M_{1}
\end{array}\right)\right|<1
$$

2.

$$
1-\operatorname{tr}\left(\begin{array}{cc}
0_{3,3} & I_{3} \\
M_{0} & M_{1}
\end{array}\right)+\operatorname{det}\left(\begin{array}{cc}
0_{3,3} & I_{3} \\
M_{0} & M_{1}
\end{array}\right)+\sum_{i=2}^{5} a_{i}>0
$$

3.

$$
1+\operatorname{tr}\left(\begin{array}{cc}
0_{3,3} & I_{3} \\
M_{0} & M_{1}
\end{array}\right)+\operatorname{det}\left(\begin{array}{cc}
0_{3,3} & I_{3} \\
M_{0} & M_{1}
\end{array}\right)+\sum_{i=2}^{5}(-1)^{i} a_{i}>0
$$

4.

$$
\left|u_{5}\right|>\left|u_{0}\right|
$$

5.

$$
\left|v_{4}\right|>\left|v_{0}\right|
$$

6.

$$
\left|w_{3}\right|>\left|w_{0}\right|
$$

7.

$$
\left|x_{2}\right|>\left|x_{0}\right|
$$

where

$$
\begin{aligned}
& u_{k}=\left|\begin{array}{ll}
a_{6} & a_{5-k} \\
a_{0} & a_{k+1}
\end{array}\right|, \quad k=0,1,2,3,4,5, \\
& v_{k}=\left|\begin{array}{ll}
u_{5} & u_{4-k} \\
u_{0} & u_{k+1}
\end{array}\right|, \quad k=0,1,2,3,4, \\
& w_{k}=\left|\begin{array}{ll}
v_{4} & v_{3-k} \\
v_{0} & v_{k+1}
\end{array}\right|, \quad k=0,1,2,3, \\
& x_{k}=\left|\begin{array}{ll}
w_{3} & w_{2-k} \\
w_{0} & w_{k+1}
\end{array}\right|, \quad k=0,1,2 .
\end{aligned}
$$

Then

$\lim _{k \longrightarrow+\infty} T_{k}=\left(I_{3}-M_{0}-M_{1}\right)^{-1} G$

where $\operatorname{tr}(M)$ is the trace of the matrix $M$ and $\operatorname{det}(M)$ the determinant of the matrix $M$.

Proof The stability of the equilibrium $S_{\mathrm{e}}=\left(I_{3}-M_{0}-\right.$ $\left.M_{1}\right)^{-1} G$ of the system (12) depends on the eigenvalues of the matrix pencil $z^{2} I_{3}-z M_{1}-M_{0}$. The characteristic equation of the matrix pencil is given by

$\operatorname{det}\left(z^{2} I_{3}-z M_{1}-M_{0}\right)=0$

or, equivalently,

$a_{0 z}^{6}+a_{1} z^{5}+a_{2} z^{4}+a_{3} z^{3}+a_{4} z^{2}+a_{5} z+a_{6}=0$,

where $a_{i}, i=0,1, \ldots, 6$, defined by (16). Note that $a_{1}=$ $-\lambda_{1}-\mu_{2}-v_{3}=-\operatorname{tr}\left(\begin{array}{cc}0_{3,3} & I_{3} \\ M_{0} & M_{1},\end{array}\right) \quad a_{6}=-\lambda_{4} \mu_{4} v_{4}=$ 
$\operatorname{det}\left(\left[\begin{array}{cc}0_{3,3} & I_{3} \\ M_{0} & M_{1} \cdot\end{array}\right]\right)$ Hence

$a_{1}=-\operatorname{tr}\left(\begin{array}{cc}0_{3,3} & I_{3} \\ M_{0} & M_{1}\end{array}\right), \quad a_{6}=\operatorname{det}\left(\begin{array}{cc}0_{3,3} & I_{3} \\ M_{0} & M_{1}\end{array}\right)$

and the above equation takes the form

$$
\begin{aligned}
& z^{6}-\operatorname{tr}\left(\begin{array}{cc}
0_{3,3} & I_{3} \\
M_{0} & M_{1}
\end{array}\right) z^{5}+a_{2} z^{4}+a_{3} z^{3}+a_{4} z^{2}+a_{5} z \\
& \quad+\operatorname{det}\left(\left[\begin{array}{cc}
0_{3,3} & I_{3} \\
M_{0} & M_{1}
\end{array}\right]\right)=0 .
\end{aligned}
$$

The equilibrium (14) of system (12) is asymptotically stable if and only if all roots of equation (29) lie within the open disk,

$$
z \in \mathbb{C}:|z|<1
$$

with $\mathbb{C}$ we denote the set of the complex numbers. Since it is usually not necessary to find the exact solutions of polynomial (29), a simple procedure to determine the existence of roots with magnitude $<1$ is the Jury's criterion which is a simple method of determining the number of these roots within the open disk (30), see Azzo and Houpis (1995), Kuo (1996), Ogata (1987). Following the Jury stability test first we compute the Jury table.

$\begin{array}{cccccccc}\text { Row } & z^{0} & z^{0} & z^{0} & z^{0} & z^{0} & z^{0} & z^{6} \\ 1 & a_{6} & a_{5} & a_{4} & a_{3} & a_{2} & a_{1} & a_{0} \\ 2 & a_{0} & a_{1} & a_{2} & a_{3} & a_{4} & a_{5} & a_{6} \\ 3 & u_{5} & u_{4} & u_{3} & u_{2} & u_{1} & u_{0} & \\ 4 & u_{0} & u_{1} & u_{2} & u_{3} & u_{4} & u_{5} & \\ 5 & v_{4} & v_{3} & v_{2} & v_{1} & v_{0} & & \\ 6 & v_{0} & v_{1} & v_{2} & v_{3} & v_{4} & & \\ 7 & w_{3} & w_{2} & w_{1} & w_{0} & & & \\ 8 & w_{0} & w_{1} & w_{2} & w_{3} & & & \\ 9 & x_{2} & x_{1} & x_{0} & & & & \end{array}$

where $u_{k}, v_{k}, w_{k}, x_{k}$ are defined by (24), (25), (26), (27), respectively. Let $P(z)=z^{6}-\operatorname{tr}\left(\begin{array}{cc}0_{3,3} & I_{3} \\ M_{0} & M_{1}\end{array}\right) z^{5}+a_{2} z^{4}+$ $a_{3} z^{3}+a_{3} z^{2}+a_{4} z+\operatorname{det}\left(\left[\begin{array}{cc}0_{3,3} & I_{3} \\ M_{0} & M_{1}\end{array}\right]\right)=0$. Then based on the Jury's criterion, the unique equilibrium (14) of system (12) is asymptotically stable if

$$
\begin{aligned}
& \left|a_{6}\right|<a_{0} ; \\
& P(1)>0 ; \\
& P(-1)>0 ; \\
& u_{5}>u_{0} \\
& v_{4}>v_{0} \\
& w_{3}>w_{0} \\
& x_{2}>x_{0} .
\end{aligned}
$$

By using (16), (28) and with easy calculations we arrive at (17)-(23). The proof is completed.
As we observe in Theorem 4.1, the government should have a reduced role and intervention into the system. Interpreting this result in economic terms we state the following case. Let consider a national economy. The economy operates properly when a sudden change (input) arrives: e.g. a catastrophic event causes a substantial reduction into the system just for 1 year. The government aims to restore the initial level of economy. Then if the government spends a lot of money next year then this may guide the whole economy to instability.

\section{Controllability and state feedback}

In this Section, we introduce concepts and results of linear control theory for time invariant linear discrete state equations. As also mentioned in "Basic assumptions", when formulating our model, the investments amount depends on a parameter which is possible to be non-constant and to be fully controlled, i.e. to be equal to

$$
G=\bar{G}_{k}
$$

Hence under this assumption system (12) takes the form

$$
T_{k+2}=M_{1} T_{k+1}+M_{0} T_{k}+\bar{G}_{k}
$$

where $M_{0}, M_{1}$, the matrices as defined for the system (12). If we set

$$
\begin{aligned}
& T_{k}=y_{k}^{1} \\
& T_{k+1}=y_{k}^{2} \\
& y_{k+1}^{1}=T_{k+1}=y_{k}^{2} \\
& y_{k+1}^{2}=T_{k+2}=M_{1} T_{k+1}+M_{0} T_{k}+\bar{G}_{k}=M_{1} y_{k}^{2}+M_{0} y_{k}^{1}+\bar{G}_{k},
\end{aligned}
$$

then by using (33) we arrive at another form of the matrix equation (32)

$$
Y_{k+1}=M Y_{k}+I_{6} G_{k},
$$

where

$$
Y_{k}=\left[\begin{array}{c}
y_{k}^{1} \\
y_{k}^{2}
\end{array}\right], \quad M=\left[\begin{array}{cc}
0_{3,3} & I_{3} \\
M_{0} & M_{1}
\end{array}\right], \quad G_{k}=\left[\begin{array}{c}
0_{3,1} \\
\bar{G}_{k}
\end{array}\right] .
$$

Since $\operatorname{det} I_{6}=1 \neq 0$, we have

$$
\operatorname{rank}\left[\begin{array}{lll}
I_{6} & M \cdot I_{6} & M^{2} \cdot I_{6}
\end{array}\right]=\operatorname{rank}\left[\begin{array}{lll}
I_{6} & M & M^{2}
\end{array}\right]=6 .
$$

The relationship (35) is the necessary and sufficient condition for the system (34) to be fully controllable with state feedback of the form

$$
G_{k}=-K Y_{k}
$$


where

$$
K=\left[K_{i j}\right]_{i=1,2, \ldots, 6}^{j=1,2, \ldots, 6} \text {. }
$$

Then by replacing (36) into (34) we get

$$
Y_{k+1}=(M-K) Y_{k}
$$

The basic problem now will be to choose the values $K_{i j}$ $i, j=1,2, \ldots, 6$, defined in (37), such that the resulting closed loop matrix equation (38) is stable. The stabilization in the time invariant case is via results on eigenvalue placement in the complex plane. In our situation eigenvalues of the closed loop system are specified to have modulus less than unity for stability. We can state the following theorem:

Theorem 5.1 Assume the system (34). Then there exists a state feedback law in the form of (36) such that the eigenvalues of the closed loop system (38) can be assigned arbitrarily as $z_{1}, z_{2}, z_{3}, z_{4}, z_{5}$ and $z_{6}$ if

$$
K=\left[\begin{array}{cccccc}
-z_{1} & 0 & 0 & 1 & 0 & 0 \\
0 & -z_{2} & 0 & 0 & 1 & 0 \\
0 & 0 & -z_{3} & 0 & 0 & 1 \\
\lambda_{4} & 0 & 0 & \lambda_{1}-z_{4} & \lambda_{2} & \lambda_{3} \\
0 & \mu_{4} & 0 & \mu_{1} & \mu_{2}-z_{5} & \mu_{3} \\
0 & 0 & v_{4} & v_{1} & v_{2} & v_{3}-z_{6}
\end{array}\right] .
$$

The values $\lambda_{i}, \mu_{i}, v_{i}, i=1,2,3,4$ are given by (13).

Proof It is known that the above problem always has a solution if and only if the system is completely controllable. Because of (35) the system (34) is controllable with state feedback in the form of (36). Then the closed loop system is given by (38). Let

$M-K=[\bar{m} i j]_{i=1,2, \ldots, 6}^{j=1,2, \ldots, 6}$.

where $M=\left[\begin{array}{cc}0_{3,3} & I_{3} \\ M_{0} & M_{1}\end{array}\right], K=\left[K_{i j}\right]_{i=1,2, \ldots, 6}^{j=1,2, \ldots, 6}$. If we want to have a targeted characteristic equation developed from targeted closed loop locations

$\Phi(z)=\left(z-z_{1}\right)\left(z-z_{2}\right)\left(z-z_{3}\right)\left(z-z_{4}\right)\left(z-z_{5}\right)\left(z-z_{6}\right)$,

where $z_{1}, z_{2}, \ldots, z_{6}$ are the targeted poles, we can set $\bar{m}_{i j}=0$, $\forall i \neq j$. Then the matrix $K$ will take the form

$$
K=\left[\begin{array}{cccccc}
K_{11} & 0 & 0 & 1 & 0 & 0 \\
0 & K_{22} & 0 & 0 & 1 & 0 \\
0 & 0 & K_{33} & 0 & 0 & 1 \\
\lambda_{4} & 0 & 0 & K_{44} & \lambda_{2} & \lambda_{3} \\
0 & \mu_{4} & 0 & \mu_{1} & K_{55} & \mu_{3} \\
0 & 0 & v_{4} & v_{1} & v_{2} & K_{66}
\end{array}\right]
$$

For the remaining values of the matrix $M-K$, i.e. $\bar{m}_{i j}$, $\forall i=j$ we have

$\bar{m}_{11}=0-K_{11}=-K_{11}$,

$\bar{m}_{22}=0-K_{22}=-K_{22}$,

$\bar{m}_{33}=0-K_{33}=-K_{33}$,

$\bar{m}_{44}=\lambda_{1}-K_{44}$,

$\bar{m}_{55}=\mu_{2}-K_{55}$,

$\bar{m}_{66}=v_{3}-K_{66}$.

Let $\Pi(z)=\operatorname{det}\left(z I_{6}-M+K\right)$ be the characteristic polynomial of the matrix (39). Then by using (41) we get

$$
\begin{aligned}
\Pi(z)= & \left(z+K_{11}\right)\left(z+K_{22}\right)\left(z+K_{33}\right)\left(z+K_{44}-\lambda_{1}\right) \\
& \times\left(z+K_{55}-\mu_{2}\right)\left(z+K_{66}-v_{3}\right) .
\end{aligned}
$$

In order to compare $\Pi(z)$ with the targeted characteristic equation $\Phi(z)$, we get

$\Pi(z) \equiv \Phi(z)$,

or, equivalently,

$-K_{11}=z_{1}$,
$-K_{22}=z_{2}$,
$-K_{33}=z_{3}$,
$\lambda_{1}-K_{44}=z_{4}$,
$\mu_{2}-K_{55}=z_{5}$,
$v_{3}-K_{66}=z_{6}$,

or, equivalently,

$K_{11}=-z_{1}$,

$K_{22}=-z_{2}$,

$K_{33}=-z_{3}$,

$K_{44}=\lambda_{1}-z_{4}$

$K_{55}=\mu_{2}-z_{5}$,

$K_{66}=v_{3}-z_{6}$.

Thus, from (40), (42), the matrix $K$ is given by

$K=\left[\begin{array}{cccccc}-z_{1} & 0 & 0 & 1 & 0 & 0 \\ 0 & -z_{2} & 0 & 0 & 1 & 0 \\ 0 & 0 & -z_{3} & 0 & 0 & 1 \\ \lambda_{4} & 0 & 0 & \lambda_{1}-z_{4} & \lambda_{2} & \lambda_{3} \\ 0 & \mu_{4} & 0 & \mu_{1} & \mu_{2}-z_{5} & \mu_{3} \\ 0 & 0 & v_{4} & v_{1} & v_{2} & v_{3}-z_{6}\end{array}\right]$

The proof is completed.

Theorem 5.1 reveals the relationship between the controllability concept, feedback action and the way that we can design the trajectories of the economy. As we observe there, we may design the eigenvalues and consequently the solution trajectories. Considering the case study mentioned in "Stability investigation", we may state that Theorem 5.1 may help the government not only to restore the stability into the economic system but also design the time path and the pattern of return. 


\section{Numerical example: system design and practical implications}

In this Section, we provide a numerical example using typical values for the parameters $m_{11}, m_{22}, m_{33}, m_{12}, m_{21}$, $m_{13}$ and $b_{1}, b_{2}, b_{3}, d_{1}, d_{2}$ of the model. Actually we consider the system (12) and assume that

$$
\begin{aligned}
& m_{11}=0.3, \quad m_{22}=0.4, \quad m_{33}=0.3, \quad m_{12}=0.3, \\
& m_{21}=0.3, \quad m_{13}=0.4 \text {, } \\
& d_{1}=0.5 \quad d_{2}=0.5 \quad b_{1}=0.3, \quad b_{2}=0.3, \\
& b_{3}=0.4 \text {. }
\end{aligned}
$$

From (13) we get

$\lambda_{1}=2 c_{1}-1.48$,

$\lambda_{2}=0.6-0.6 c_{1}$,

$\lambda_{3}=0.8 c_{1}$,

$\lambda_{4}=-0.18$,

$\mu_{1}=0.3$,

$\mu_{2}=0.31$,

$\mu_{3}=0.4$

$\mu_{4}=-0.21$,

$v_{1}=0.6-0.6 c_{1}$,

$v_{2}=0.6 c_{1}$,

$v_{3}=0.58-0.8 c_{1}$,

$v_{4}=-0.28$.

In addition from (16) we have

$a_{0}=1$,

$a_{1}=0.59-1.2 c_{1}$,

$a_{2}=-1.12 c_{1}^{2}+2.176 c_{1}-0.6474$,

$a_{3}=0.6832 c_{1}^{2}-1.56144 c_{1}+0.582904$,

$a_{4}=-0.2352 c_{1}^{2}+0.5276 c_{1}-0.179764$,

$a_{5}=0.049476-0.08736 c_{1}$,

$a_{6}=0.010584$.

By using Theorem 4.1 we may determine the value of $c_{1}$ parameter such that the system is stable, i.e. in order to obtain asymptotic stability in the system of national economy. So, we use conditions of Theorem 4.1, the given values in (43) and we target boundary values for parameter $c_{1}$. The condition (17) is always satisfied. From (18) and taking into account that $c_{1}>0$, we get $0<c_{1}<1.34236$. From (19) we get $0.202116<c_{1}<2.52178$. By combining the rest of the conditions (20)-(23) and the previous expessions we get the following open interval for $c_{1}$

$$
0.202116<c_{1}<1.34236 \text {. }
$$

Hence, the system is asymptotically stable if and only if (44) is satisfied. Now, we can further design the value for parameter $c_{1}$ targeting to a high speed response system. The speed of the system's response is basically characterized by the maximum value $r$ of the following set $r=\max _{1 \leq i \leq 6}\left\{\left|\rho_{i}\right|\right\}$

where $\rho_{i}, i=1,2, \ldots, 6$ are the roots of the respective characteristic polynomial (29) associated with the characteristic equation of the matrix pencil of the system (12). So, high speed response coincides with minimizing the value of $r$. We may minimize $r$ with a strict mathematical process and obtain optimal value.

We notice that as $c_{1}$ approaches the values 0.20116 and 1.34236, $r$ approaches the value 1 . For $c_{1}=0.6 \pm \epsilon$, the system is stable and returns very fast to initial conditions.

\section{Conclusions}

In this paper we study the stability of equilibrium for a foreign trade model of three countries. We assume that national income equals consumption outlays plus net investment plus exports minus imports. Then, we employ delayed difference equations of sixth order to describe the model, while the respective solutions of sixth order polynomial correspond to the typical observed business cycles of real economy.

Closing the paper, we may argue that the specific research effort is not only a theoretical extension of basic versions of foreign trade models, but also a practical guide for controlling the parameters of national economy system. It investigates the stability and controllability concepts producing analytical conditions and solutions. These conditions enable the decision makers to obtain stable trajectories for the expectation of national income values. Further research is carried out for even higher order equations investigating qualitative results.

\begin{tabular}{ll}
\hline Parameter $c_{1}$ & Maximum value $r$ \\
\hline 0.2 & 1.00461 \\
0.21 & 0.982723 \\
0.3 & 0.770499 \\
0.4 & 0.48135 \\
0.5 & 0.478544 \\
0.6 & 0.475617 \\
0.7 & 0.537831 \\
0.8 & 0.567141 \\
0.9 & 0.562829 \\
1 & 0.549309 \\
1.1 & 0.615346 \\
1.2 & 0.776889 \\
1.3 & 0.932511 \\
1.4 & 1.09371 \\
1.5 & 1.26089 \\
\hline
\end{tabular}


Finally, a straightforward result is the evidence support for the fact that individuals and institutions have long memory and base their decisions for investment and/or consumption accordingly. The paper restores the inadequacy of other trade foreign models that couldn't produce stable business cycles for the typical realistic values of the multiplier and accelerator parameters. That is obtained via the existence of sixth order difference equations, resulting from the delay concept. These equations produce complex solutions and consequently oscillatory trajectories where under certain circumstances can be designed to be stable.

\section{Acknowledgments I. Dassios is supported by EPSRC Grant EP/} I017127/1.

Open Access This article is distributed under the terms of the Creative Commons Attribution License which permits any use, distribution, and reproduction in any medium, provided the original author(s) and the source are credited.

\section{References}

Alenikov BI, Davidovi GZ, Fomin BS (1969) A block approach to the solution of optimization problems in foreign trade. In: (Russian) Economic-mathematical models (Suppl. to konom. i Mat. Metody), Collection No. 2 (Russian), pp 7177. Izdat. Nauka, Moscow

Anderson JE (1979) A theoretical foundation for the gravity equation. Am Econ Rev 69(1):106-116

Anderson JE, van Wincoop E (2003) Gravity with gravitas: a solution to the border puzzle. Am Econ Rev 93(1):170-192

Azzo JD, Houpis CH (1995) Linear control system analysis and design, 4th edn. Mc Graw-Hill, USA

Brems H (1956) The foreign trade accelerator and the international transmission of growth. Econometrica 24:223-238

Bond E, Driskill R (2009) Multiplicity and stability of equilibrium in trade models with durable goods. International trade and economic dynamics. Springer, Berlin, pp 281-297

Cabo F, Martn-Herrn G, Martnez-Garca MP (2008) Technological leadership and sustainable growth in a bilateral trade model. Int Game Theory Rev 10(1):73-100

Cabo F, Martn-Herrn G, Martnez-Garca MP (2014) Property rights for natural resources and sustainable growth in a two-country trade model. Decis Econ Finance 37(1):99-123

Chaney T (2008) Distorted gravity: the intensive and extensive margins of international trade. Am Econ Rev 98(4):1707-1721

Chaney T (2011) The network structure of international trade. NBER WP, Combes

Chari VV (1994) Optimal fiscal policy in a business cycle model. J Polit Econ 102(4):52-61

Chow GC (1985) A model of Chinese national income determination. J Polit Econ 93(4):782-792

Dassios I, Kontzalis C (2012) On the stability of equilibrium for a foreign trade model. In: Proceedings of the 32nd IASTED international conference

Dassios I, Kontzalis C, Kalogeropoulos G (2012) A stability result on a reformulated Samuelson economical model. In: Proceedings of the 32nd IASTED international conference

Day R (1999) Complex economic dynamics: an introduction to macroeconomic dynamics, vol 2. MIT Press, Cambridge
Dorf RC (1983) Modern control systems, 3rd edn. Addison-Wesley, USA

Eaton, J, Samuel K, Francis K. Forthcoming. An anatomy of international trade: evidence from French firms, Econometrica 19

Gcke M (2001) A macroeconomic model with hysteresis in foreign trade. Metroeconomica 52(4):449-473

Hager WW, Garg DP (1972) Dynamics of a non-linear spatial trade model. Int J Syst Sci 3:427-438

Horiba Y, Moroney JR (1979) On the structure of comparative advantage in a multifactor trade model. Int Econ Rev 20(2):551-554

Huang H, Whalley J, Zhang (2009) Shunming exploring policy options in joint intertemporal-spatial trade models using an incomplete markets approach. Econom Theory 41(1):131-145

Jones RW (2012) General equilibrium theory and competitive trade models. Int J Econ Theory 8(2):149-164

Jones RW, Marjit S (2009) Competitive trade models and real world features. Econom Theory 41(1):163-174

Jones RW (1975) Income distribution and effective protection in a multicommodity trade model. J Econom Theory 11(1):1-15

Kokot S (2004) The econometrics of sequential trade models. Theory and applications using high frequency data. Lecture Notes in Economics and Mathematical Systems, 538. Springer Berlin

Korobko TV. A trade model with endogenous savings, net consumptions, and leisure time. (Ukrainian) Vsn Kiv Unv Ser Fz-Mat Nauki 2000(3):247-251

Koyck LM (1953) Long-term foreign trade elasticities. A Note Metroecon 5:61-67

Krelle W (1987) Structural change induced by foreign trade. What are the advantages for the country? konomie und Mathematik. Springer, Berlin, pp 566-598

Krugman P (1980) Scale economies product differentiation, and the patterns of trade. Am Econom Rev 70(5):950-959

Kuo BC (1996) Automatic control systems, 5th edn. Prentice Hall, USA

Luke DW, Breakwell JV (1978) Optimal economic growth with foreign trade and a learning industry. J Optim Theory Appl 24

Nagy A, Stahl J (1967) The optimal volume of foreign trade and the exchange rate. Econometrica 35:143-153

Mansur A, Whalley J (1982) A decomposition algorithm for general equilibrium computation with application to international trade models. Econometrica 50(6):1547-1557

Mikhalevich MV, Sergienko IV, Koshla LB (2001) Modeling foreign trade activity under transitional economy conditions. (Russian) Kibernet Sistem Anal 2001(4):61-84, 189. Translation in Cybernet Systems Anal 37(4):515-532

Mycielski, J, Rey K, Trzeciakowski W (1963) Partial and general optimum in planning foreign trade. (Polish) Przeglad Statyst 10:119-137

Ogata K (1987) Discrete time control systems. Prentice Hall, USA

Puu T, Gardini L, Sushko I (2004) A Hicksian multiplier-accelerator model with floor determined by capital stock. J Econom Behav Organ 56

Rosser JB (2000) From catastrophe to chaos: a general theory of economic discontinuities. Academic Publishers, Boston

Santos Silva JMC, Tenreyro S (2006) The log of gravity. Rev Econom Stat 88:641-658

Samuelson P (1939) Interactions between the multiplier analysis and the principle of acceleration. Rev Econom Stat

Van der Laan G (1990) General equilibrium in a closed international trade model. Nieuw Arch Wisk (4) 8(3):347-359

Westerhoff FH (2006) Samuelson's multiplier-accelerator model revisited. Appl Econom Lett 56:86-92

Whalley J, White PMC (1985) A decomposition algorithm for general equilibrium computation with application to international trade models [Econometrica 50 (1982), no. 6, 15471557; MR0685336 
(84f:90021)] by A. Mansur and Whalley. Econometrica 53(3):679

Wincoop E (1996) A multi-country real business cycle model. Scand J Econom 23:233-251

Yano M (1990) von Neumann facets and the dynamic stability of perfect foresight equilibrium paths in neo-classical trade models. Z Nationalkonom 51(1):27-69
Yu L, Wang S, Lai KK (2008) Forecasting China's foreign trade volume with a kernel-based hybrid econometric-AI ensemble learning approach. J Syst Sci Complex 21(1):1-19

Zhu H, Huang W (2007) Comparative dynamics in a stochastic growth and trade model with a variable savings rate. Stochastic economic dynamics. Copenhagen Business School Press, Frederiksberg, pp 217-228 